Rahim İçi Baba Bağlanma Ölçeği'nin (RỉBBÖ) Geliştirilmesi

\title{
Development of The Father's Attachment Scale in Intrauterine Period
}

\section{Sevgül Dönmez ${ }^{1}$, Süreyya Gümüşsoy ${ }^{2}$}

1Muğla Sıtkı Kocaman Üniversitesi Sağlık Bilimleri Fakültesi, Muğla, Türkiye

2Ege Üniversitesi Atatürk Sağlık Hizmetleri Meslek Yüksekokulu, İzmir, Türkiye

\section{$\ddot{O} Z$}

GIRIŞ ve AMAÇ: Babalık rolü gebeliğin teşhis edilmesiyle başlar ve doğumu takip eden aylarda gelişir. Tipkı anne gibi baba da gebelik süresince, bağlanma davranışlarını geliştirir. Baba, eşinin karninda bebeğin hareketlerini hissettiğinde, çocuk ile doğrudan ilişsisi başlar. Bu araştırma, Rahim İçi Baba Bağlanma Ölçeği'nin (RIBBÖ) geliştirilmesi, ölçeğin geçerlilik ve güvenilirlik çalışmasının yapılması amacıyla planlanmıştır.

YÖNTEM ve GEREÇLER: Araştırma, Kasım 2017-Nisan 2018 tarihleri arasındaki rutin gebelik kontrolü için başvuran 24-38 haftalık gebelerin eşleri ile metodolojik olarak yapılmıştır. 23 maddeden oluşan RIBBÖ'nün uygulamasında 158 babaya ulaşılmıştır. Ölçeğin geçerlik ve güvenirlik analizleri korelasyon analizi, Cronbach alpha güvenirlik katsaylst, Kendall W testi, Kaiser Meyer Olkin ve Barlett's Test yöntemleri kullanılmıştır.

BULGULAR: Ölçeğin kapsam geçerliliği analizine göre uzmanların tarafindan ölçek maddelerine verilen puanlar arasinda istatistiksel olarak anlamlı bir fark bulunmamıştır (Kendall's $W=0.256$; $p=0.705$ ). RIBBBÖ'nün tüm maddeleri için Cronbach alfa değeri 0.73 'dür. Ölçekten bir madde çıkarıldiğında yeniden hesaplanan Cronbach Alpha katsayılarının tamamı, tüm soruların yer aldığı ölçeğin Cronbach Alpha katsaylsından daha düşük bulunmuştur. RIBBÖ'nün yapı geçerliliği analizi için Kaiser Meyer Olkin (KMO) Testi ve Barlett's Testi kullanılmış ve ölçekten elde edilen verilerin faktör analizi için uyumlu olduğu sonucuna varılmıştır $(K M O=0.861 ; p<0.05)$.

TARTIŞMA ve SONUÇ: Çalışmanın sonucunda RIBBBÖ'nün eşleri 24-38 haftalık gebelik döneminde olan babaların, bebeklerine bağlanma durumlarının belirlenmesinde geçerligüvenilir bir ölçek olarak kullanılabileceği sonucuna varılmıştır.

Anahtar Kelimeler: Bağlanma, baba, fetüs, gebelik

\begin{abstract}
INTRODUCTION: The paternity role begins with the diagnosis of pregnancy and develops in the months following birth. Like mother, father also develops attachment behaviors during pregnancy. When the father feels the baby's movements in the womb, a direct relationship with the child begins. The aim of this study was to develop the Intrauterine Father Attachment Scale and to perform the validity and reliability of the scale.
\end{abstract}

METHODS: The study was performed methodologically with the spouses of the pregnant women between 24-38 weeks of age who applied for routine pregnancy control between November 2017 and April 2018. In the implementation of the scale, consisting of 23 items, 158 fathers were reached. Correlation analysis, Cronbach's alpha reliability coefficient, Kendall W test, Kaiser Meyer Olkin and Barlett's Test methods were used.

RESULTS: According to the scale's validity analysis, there was no statistically significant difference between the scores given by the experts to the scale items (Kendall göres $W=0.256 ; p=0.705)$. The Cronbach's alpha value for all items of the scale is 0.73. The Cronbach Alpha coefficients were lower than the Cronbach Alpha coefficient of the scale. Kaiser Meyer Olkin (KMO) Test and Barlett's Test were used for the structure validity analysis of the scale and it was concluded that the data obtained from the scale were compatible for factor analysis $(K M O=0.861 ; p<0.05)$.

DISCUSSION and CONCLUSION: It was concluded that the fathers who were at 24-38 weeks gestational age of the scale could be used as a valid-reliable scale in determining the attachment status of their babies

Keywords: Attachment, father, fetus, pregnancy

Iletişim / Correspondence:

Dr. Sevgül Dönmez

Muğla Sitkı Kocaman Üniversitesi Sağlık Bilimleri Fakültesi, Muğla, Türkiye

E-mail: sureyya.s@hotmail.com

Başvuru Tarihi: 19.07.2018

Kabul Tarihi: 24.04.2019 


\section{GİRIŞ}

Bağlanma davranış1, başka bir bireye karşı yakınlık arama ve sürdürme olarak tanımlanmıştır. $\mathrm{Bu}$ teori bakım veren ile çocuk arasındaki bilişsel, duygusal ve davranışsal ilişkiyi açıklamaktadır $(1,2)$. Bağlanma bebek ile birincil bakım veren kişi arasında gelişen ve bebekte güven duygusunu yerleştiren güçlü bir bağdır. Bağlanma iki taraflı bir ilişkidir ve her iki tarafın da birbirinin ihtiyaçlarını karşılaması ile gelişir. Duygusal bağ kurma bebeklerin yaşamlarını sürdürebilmesi ve gelişebilmesi için gereklidir (3). Doğum öncesi bağlanma bebek doğmadan önce anne karnındaki bebek ve ebeveynler arasındaki kendine özgü ilişkiyi ifade etmektedir (4). Yapılan araştırmalar incelendiğinde, anne-babanın çocuklarına yaklaşım biçimlerinin, onların kişilik özelliklerinin biçimlenmesinde etkili olduğu sonucunu çıkarmıştır ve çocukların birincil bakım veren kişiler yönünde, özellikle anneye bağlanmanın gerçekleştiğini, ancak çocukların babalarına da bağlanma duygularının olduğunu belirtmiştir. Ancak çocuğun ruhsal gelişiminde annenin rolü çok fazla araştırılan bir konu olmasına karşın, babanın rolü konusunda yapılan araştırmaların sayısı oldukça azdır $(1,5)$. Genellikle bağlanma üzerine yapılan araştırmalar baba için de anneye benzer bir süreç göstermeye meyillidir. Tıpkı anne gibi baba da gebelik süresince, bağlanma davranışlarını geliştirir. Baba, eşinin karnında bebeğin hareketlerini hissettiğinde, çocuk ile doğrudan ilişkisi başlar. Babanın annenin karnında yeni yaşamı hissetmesi çoğunlukla baba bebek ilişkisini ve oyun oynamaları başlatır. Babalık rolü gebeliğin teşhis edilmesiyle başlar ve doğumu takip eden aylarda gelişir (6). Anne-bebek, bababebek etkileşiminin çocuğun gelişimi ve tüm yaşamını etkilemesi nedeniyle ebe/hemşire/doktorlara doğum öncesi, doğum ve doğum sonrası dönemde önemli sorumluluklar düşmektedir (7).

$\mathrm{Bu}$ araştırma, Rahim İçi Baba Bağlanma Ölçeği'nin (RİBBÖ) geliştirilmesi, ölçeğin geçerlilik ve güvenilirlik çalışmasının yapılması amacıyla planlanmıştır.

\section{GEREÇ VE YÖNTEMLER}

Araştırma, Gaziantep şehrinde bir kamu hastanesi Kadın Hastalıkları ve Doğum Polikliniklerinde Kasım 2017-Nisan 2018 tarihleri arasındaki rutin gebelik kontrolü için başvuran 24-38 haftalık gebelerin eşleri ile metodolojik olarak yapılmıştır. Araştırmanın örneklemini, gönüllü, evli olan, 18 yaş üstü, daha önce psikiyatrik bir hastalığı bulunmayan, okuma yazma ve Türkçe bilen, eşleri 24-38 haftalık gebe olan 158 baba oluşturmuştur. Literatürde, ölçek geliştirme çalışmalarında alınacak örneklem büyüklügünün madde sayısının en az 5-10 katı civarında olması gerektiği belirtilmektedir (8). Ayrıca araştırmanın verileri ile G-Power Data Analysis programıyla post-hoc güç analizi yapılmıştır. Güç analizinde örneklem büyüklügü 158 olarak alınmış ve güç analizi \%95 güven aralığı ve $\mathrm{p}=0.05$ anlamlılık düzeyinde hesaplanmıştır. Araştırmanın gücü 0.99, etki düzeyi ise 0.25 orta düzey olarak belirlenmiş ve örneklem sayısının evreni temsil gücünün iyi olduğu sonucuna ulaşılmıştır.

\section{Veri Toplama Aracı ve Uygulanması}

Veri toplama aracı olarak iki bölümden oluşan anket formu kullanılmıştır. Anket formunun birinci bölümünde, araştırmacı tarafından ilgili literatür doğrultusunda hazırlanan babaların tanıtıcı özelliklerini içeren "Tanıtıcı Bilgi Formu", ikinci bölümde ise babaların rahim içi bebeğe bağlanma düzeyinin belirlenmesi amacıyla araştırmacı tarafindan hazırlanan "Rahim İçi Baba Bağlanma Ölçeği” yer almıştır. Bu ölçek ile babaların rahim içi bebeğe bağlanma düzeyleri ölçülecektir. Likert tipi ölçeğin yanıt seçenekleri olan; hiçbir zaman (1), bazen (2), çoğunlukla (3), her zaman (4) seçeneklerinden birini seçmeleri istenmiş, puanlar ankette belirtilmemiştir.

Geliştirilmesi planlanan ölçek formunun uygulanabilmesi için öncelikle Gaziantep Üniversitesi Klinik Araştırmaları Yerel Etik Kurul Başkanlığı'ndan (No:379), ilgili hastaneden yazılı izin alınmıştır. Ölçeğin uygulanması, Kasım 2017Nisan 2018 tarihleri arasında gerçekleştirilmiştir. Örneklem kapsamına alınan babalara araştırmanın amacı açıklanarak, araştırmaya katılımın tamamen gönüllük esasına dayandığı ve istediklerinde 
araştırmadan çekilebilecekleri belirtilerek "Tanılama Formu" ve ölçeği doldurmaları istenmiştir. Araştırmanın örneklem kapsamına alınan babalara yaş, eğitim durumu, çalışma durumu gibi sosyo-demografik özelikleri içeren "Tanılama Formu" ve ölçek Kasım 2017-Nisan 2018 tarihleri arasında uygulanmıştır. Veri toplama araçlarının uygulanması yaklaşı 10-15 dakika sürmüştür. Babaların veri toplama araçlarını bireysel olarak doldurmaları sağlanmıştır.

\section{Verilerin Değerlendirilmesi}

Araştırmadan elde edilecek verilerin analizi SPSS 22.0 paket programında gerçekleştirilecektir. Ölçeğin kapsam geçerliliği için Kendall's W testi kullanılmıştır. Ölçeğin güvenirliğinin değerlendirilmesi için iç tutarlık analizi olarak Cronbach alfa, madde güvenirliği için madde toplam puan korelasyonları değerlendirmesi yapılmıştır. Ölçeğin yap1 geçerliliğinin belirlenmesinde Kaiser Meyer Olkin (KMO) Testi ve Barlett's Testi kullanılmıştır.

\section{BULGULAR}

\section{Kapsam (İçerik) Geçerliliği}

Geliştirilen ölçek için öncelikle konu ile ilgili literatür taranmıştır (1-4,7). Literatür tarandıktan sonra bir form oluşturulmuştur. Bu form 20 babadan oluşan küçük bir grubun görüşüne sunulmuş ve bebekleriyle ilgili benzer düşünceleri yazmaları istenmiştir. Babalarla görüşüldükten sonra ölçek yeniden düzenlenmiştir. Bu çalışma ile yeni bir soru havuzu oluşturulmuştur. $\mathrm{Bu}$ soru havuzunda birbirine çok benzeyen maddeler birleştirilmiş veya çıkarılmıştır. Bunun sonucunda, belirlenen madde sayısının olduğu form elde edilmiştir. Bu formun, uygunluğu ve anlaşılırlığının değerlendirmesi için, üç kadın doğum uzmanı, bir ruh sağlığı uzmanı, bir klinik psikolojik danışman olmak üzere toplam 5 uzmanın görüşüne sunulmuştur ve çoğul uzman görüşüne dayalı içerik geçerliliği sağlanmıştır. Uzmanlar ölçek maddelerini anlaşılırlık ve amaca uygunluk açısından incelemiş ve her maddenin ölçme değerini 1 ile 4 puan üzerinden $(1=$ uygun değil, 2=maddenin uygun şekilde değiştirilmesi gerekiyor; 3=Uygun, fakat ufak değişiklik gerekiyor; 4=Çok uygun) puanlayarak görüşlerini belirtmişlerdir. Uzmanların ölçek maddelerine verdikleri puanların uyumunu ölçmek için yapılan Kendall's Uyuşum Katsayısı analizi sonucunda, uzmanlar tarafından ölçek maddelerine verilen puanlar arasında istatistiksel olarak anlamlı bir fark bulunmamıştır (Kendall's W=0.256; $\mathrm{p}=0.705$ ). Uzman görüşleri alındıktan sonra form yeniden yapılandırılmıştır. Ölçeğin son şekli 4'lü likert tipinde derecelendirme ile düzenlenerek 15 kişilik baba grubuna pilot uygulama yapılarak ifadelerin anlaş1lırlığ tekrar test edilmiş, Pearson momentler çarpımı korelasyon sonucunda uyumlu bulunmuştur.

\section{İç Tutarlıık Analizi}

Ölçeğin tüm maddeleri için Cronbach alfa değeri 0.737 bulunmuştur. Ölçekten bir madde çıkarıldığında yeniden hesaplanan Cronbach Alpha katsayılarının tamamı, tüm soruların yer aldığı ölçeğin Cronbach Alpha katsayısından daha düşük bulunmuştur (Tablo 1). Ölçeğin üç maddesinin madde toplam korelasyonu 0.30 altında bulunmuş ve bu üç madde ölçekten çıkarılarak ölçek 23 madde ile son şeklini almıştır.

\section{Yapı Geçerliliği (Faktör Analizi)}

RİBBÖ’nün yapı geçerliliği analizi için Kaiser Meyer Olkin (KMO) Testi ve Barlett's Testi kullanılmış ve ölçekten elde edilen verilerin faktör analizi için uyumlu olduğu sonucuna varılmıştır $(\mathrm{KMO}=0.861 ; \mathrm{p}<0.05)$. Ayrica verilerin normal dağılıp dağılmadığını değerlendirmek için Bartlett Sphericity testi kullanılmıştır. Bartlett Sphericity testine göre istatistiğinin anlamlı çıkması elde edilen verilerin normal dağılım gösterdiği anlamına gelmektedir (Tablo 2). Rahim İçi Baba Bağlanma Ölçeği (RİBBÖ), babanın doğum öncesi fetusa bağlanmasını ölçmekte ve toplam 23 maddeden oluşan tek faktörlü bir ölçektir. Ölçek 4'lü Likert olarak geliştirilmiş ve her bir maddede belirtilen ifadeye "Hiçbir zaman=1 puan", "Bazen=2 puan", "Çoğunlukla=3 puan" ve "Her zaman=4 puan seçeneklerinden birini seçmesi istenmektedir. Ölçek maddelerinin diğer maddeler ile negatif yönde bir ilişkiye sahip olması durumunda, bu maddeler ters skorlanmaktadır. $\mathrm{Bu}$ ölçekte de, yer alan 23 maddeden 17, 18, 20, 22 ve 23. maddenin ifadeleri tersine kodlanmaktadır. Ölçekten alınabilecek toplam puan 23 ile 92 arasında değişmekte olup, 
Tablo 1. RİBBÖ Madde Analizi Sonuçları (n=158)

\begin{tabular}{|c|c|c|c|c|}
\hline Maddeler & $\begin{array}{l}\text { Madde- } \\
\text { Toplam Puan } \\
\text { Korelasyonu }\end{array}$ & $\begin{array}{l}\text { Madde } \\
\text { silindiğinde } \\
\text { Cronbach's } \\
\text { Alpha }\end{array}$ & $\begin{array}{l}\text { Ortalama } \pm \\
\text { Standart } \\
\text { Sapma }\end{array}$ & Min-Max \\
\hline 1. Bebeğimle konuşurum & .432 & .728 & $2.32 \pm 0.89$ & $1-4$ \\
\hline 2. Eşimin karnına dokunarak bebeğimi hissederim. & .475 & .728 & $2.41 \pm 0.82$ & $1-4$ \\
\hline 3. Bebeğime doğmadan ismi ile çağırırım & .310 & .731 & $2.12 \pm 0.91$ & $1-4$ \\
\hline $\begin{array}{l}\text { 4. Eşimin karnına dokunduğumda bebeğimin } \\
\text { uyuduğunu hissederim }\end{array}$ & .398 & .729 & $2.21 \pm 0.88$ & $1-4$ \\
\hline 5. Bebeğimin doğması için sabırsızlanıyorum & .730 & .720 & $2.77 \pm .0 .90$ & $1-4$ \\
\hline 6. Bebeğim ile ilgili hayaller kurarım & .678 & .722 & $2.60 \pm 0.84$ & $1-4$ \\
\hline 7. Bebeğim için bir şeyler alırım & .714 & .719 & $2.65 \pm 0.92$ & $1-4$ \\
\hline $\begin{array}{l}\text { 8. Bebeğimin odasını hazırlamaktan büyük mutluluk } \\
\text { duyarım }\end{array}$ & .664 & .722 & $2.58 \pm 0.87$ & $1-4$ \\
\hline 9. Bebeğimin beni duyduğunu bilirim & 659 & .721 & $2.43 \pm 0.96$ & $1-4$ \\
\hline 10. Bebeğimin kime benzediğini merak ederim & .629 & .721 & $2.75 \pm 097$ & $1-4$ \\
\hline 11. Bebeğimin güvende olduğunu bilirim & 620 & .722 & $2.70 \pm 0.94$ & $1-4$ \\
\hline $\begin{array}{l}\text { 12. Bebeğimle konuştuğum zaman kendimi mutlu } \\
\text { hissediyorum }\end{array}$ & .780 & .718 & $2.75 \pm 0.90$ & $1-4$ \\
\hline $\begin{array}{l}\text { 13. Bebeğime karşı güçlü duygularım olduğunu } \\
\text { hissediyorum }\end{array}$ & .763 & .717 & $2.79 \pm 0.96$ & $1-4$ \\
\hline 14. Bebeğimin huzursuz olduğunu hissedebilirim & .442 & .727 & $2.44 \pm 0.96$ & $1-4$ \\
\hline $\begin{array}{l}\text { 15. Bebeğimle ilgili duygularımı, planlarımı çevremde } \\
\text { paylaşmaktan hoşlanırım }\end{array}$ & .330 & .730 & $2.41 \pm 0.99$ & $1-4$ \\
\hline 16. Eşim yanımda olmadığında, bebeğimi düşünürüm & .488 & .727 & $2.65 \pm 0.80$ & $1-4$ \\
\hline $\begin{array}{l}\text { 17. Bebeğim nedeniyle vazgeçmek zorunda kaldığım } \\
\text { şeyleri düşününce sinirleniyorum }\end{array}$ & .530 & .733 & $3.03 \pm 0.91$ & $1-4$ \\
\hline $\begin{array}{l}\text { 18. Eşimin sağllğı ile ilgili kendine dikkat etmediğini } \\
\text { düşünürsem, bebeğime zarar geleceğini düşünüp } \\
\text { sinirlenirim }\end{array}$ & -.320 & .731 & $2.44 \pm 0.94$ & $1-4$ \\
\hline 19. Bebeğime karşı sevgi doluyum & .599 & .723 & $2.97 \pm 0.90$ & $1-4$ \\
\hline 20. Bebeğim bende gerginlik yaratıyor & .320 & .733 & $3.01 \pm 0.90$ & $1-4$ \\
\hline $\begin{array}{l}\text { 21. Benim bebeğimin, dünyadaki en güzel bebek } \\
\text { olacağına inanıyorum }\end{array}$ & .626 & .721 & $3.00 \pm 0.90$ & $1-4$ \\
\hline $\begin{array}{l}\text { 22. Bebeğim doğduğunda kucağıma bir süre } \\
\text { alamamaktan korkuyorum }\end{array}$ & -.470 & .730 & $2.93 \pm 0.97$ & $1-4$ \\
\hline 23. Bebek benim değilmiş gibi hissediyorum & -.410 & .730 & $3.61 \pm 0.85$ & $1-4$ \\
\hline \multicolumn{3}{|l|}{ Cronbach Alpha $=0.737$} & $61.67 \pm 10.55$ & 43-85 \\
\hline
\end{tabular}

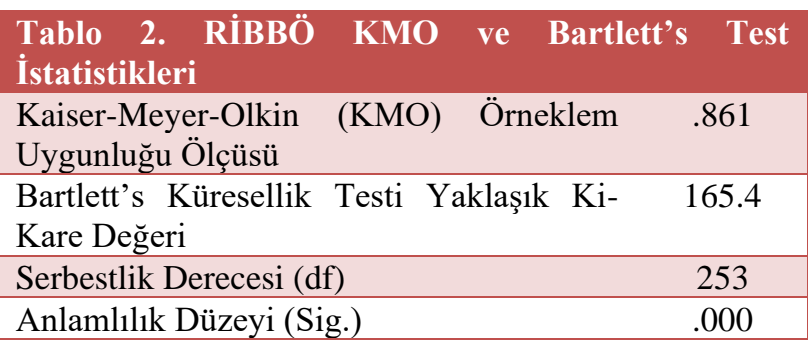

alınan yüksek puanlar babanın doğum öncesi fetusa bağlanma düzeyinin yüksek; düşük puanların ise babanın doğum öncesi fetusa bağlanma düzeyinin düşük olduğu anlamına gelmektedir.
$\mathrm{Bu}$ çalışmadaRİBBÖ toplam puan ortalaması $61.67 \pm 10.55 \quad(\min =43, \quad \max =85)$ bulunmuştur. Ölçekte yer alan tüm maddelerin ortalamaları Tablo l'de sunulmuştur.

Ölçek Tablo 3'de sunulmuştur. 


\section{Tablo 3. Rahim İçi Baba Bağlanma Ölçeği (RỉBBÖ)}

\section{MADDELER}

1. Bebeğimle konuşurum

2. Eşimin karnına dokunarak bebeğimi hissederim.

3. Bebeğime doğmadan ismi ile çağırırım

4. Eşimin karnına dokunduğumda bebeğimin uyuduğunu hissederim

5. Bebeğimin doğması için sabırsızlanıyorum

6. Bebeğim ile ilgili hayaller kurarım

7. Bebeğim için bir şeyler alırım

8. Bebeğimin odasını hazırlamaktan büyük mutluluk duyarım

9. Bebeğimin beni duyduğunu bilirim

10. Bebeğimin kime benzediğini merak ederim

11. Bebeğimin güvende olduğunu bilirim

12. Bebeğimle konuştuğum zaman kendimi mutlu hissediyorum

13. Bebeğime karşı güçlü duygularım olduğunu hissediyorum

14. Bebeğimin huzursuz olduğunu hissedebilirim

15. Bebeğimle ilgili duygularımı, planlarımı çevremde paylaşmaktan hoşlanırım

16. Eşim yanımda olmadığında, bebeğimi düşünürüm

17.Bebeğim nedeniyle vazgeçmek zorunda kaldığım şeyleri düşününce sinirleniyorum

18.Eşimin sağlığ1 ile ilgili kendine dikkat etmediğini düşünürsem, bebeğime zarar geleceğini düşünüp sinirlenirim

19. Bebeğime karşı sevgi doluyum

20. Bebeğim bende gerginlik yaratıyor

21. Benim bebeğimin, dünyadaki en güzel bebek olacağına inanıyorum

22. Bebeğim doğduğunda kucağıma bir süre alamamaktan korkuyorum

23. Bebek benim değilmiş gibi hissediyorum

\section{TARTIŞMA}

Günümüzde erkekler, geçmişte kendi babaları tarafindan hayal edilemeyecek kadar gebelik ve doğum sürecine dahil edilmekte ve artık deneyimledikleri bu güçlü duygusal boyutları fark edip isimlendirebilmektedir. Bir babanın fetüsle olan ilişkisini anlamak için babanın iç dünyasını ve gebelik süresince duygu durumunu keşfetmeyi, gelişmekte olan bebeği ile ilgili zihninde oluşturduğu tabloyu ve bu bebeğin babası olma fikrini anlamayı gerektirmektedir (10). Bu çalışma, babanın rahim içi fetüse bağlanma düzeyini belirleyen RİBBÖ'nün geliştirilmesi amaciyla yapılmıştır.

Bir özelliğin gözlemlenip, gözlem sonucunun sayı ve sembollerle gösterilmesi ölçme olarak tanımlanmaktadır. Geçerlilik, uygulanan ölçeğin araştırıcının ölçmeyi düşündüğü değişkeni gerçekten yetkin bir şekilde doğru olarak ölçüp ölçmediğini göstermektedir. Bir ölçüm aracının geçerli olarak kabul edilebilmesi için gerekli olan ilk koşul güvenilir olmasıdır. Güvenilirlik ise, aynı aşamalardan geçilmesi ve aynı yöntemlerin kullanılması durumunda sonuçların aynı alınması anlamına gelmektedir $(11,12)$. Ölçüm aracının hem doğru ve güvenilir ölçüm yapması hem de kullanılma amacına hizmet etmesi gerekir. $\mathrm{Bu}$ nedenle ölçme araçları geliştirilirken güvenirliğinin ve geçerliğinin her ikisine birden bakılması gereklidir $(13,14)$.

Gebelik döneminde babaların bebeğine bağlanma durumlarını ölçmek için kullanılacak olan RIBBÖ’nün geçerlilik ve güvenirliğinin belirlenmesinin planlandığ literatür taraması ve babaların görüşüne başvurularak araştırmacılar tarafından oluşturulan form, kapsam geçerliliğini yapmak amacıyla uygunluğunun ve anlaşılırlığının değerlendirmesi için, üç kadın doğum uzmanı, bir ruh sağlığı uzmanı, bir klinik psikolojik danışmandan oluşan toplamda 
beş uzmanın görüşüne başvurulmuştur ve çoğul uzman görüşüne dayalı içerik geçerliliği sağlanmıştır. Literatürde geliştirilmek istenen ölçekteki konu ile ilgili bu alanda yeterli olan en az 5 en fazla 40 uzmanın görüşünün alınması gerektiği belirtilmektedir (15). Ölçekteki 23 maddenin içerik geçerliliği için beş uzmanın verdiği puanlara göre yapılan Kendall Uyuşum Katsayısı korelasyon testi (Kendall's W=0.256; p=0.705) yapılmıştır. Söz konusu uzmanların ölçeğin maddelerine verdiği puanlar arasında istatistiksel olarak anlamlı bir fark bulunmamıştır. Bu sonuca dayanarak uzmanların ölçeğin maddelerinin içeriği konusunda görüş birliğine vardıkları söylenebilir.

Ölçeğin yapı geçerliliğini belirlemek için açıklayıcı faktör analizi yöntemi kullanılmıştır. Faktör analizi, aralarında ilişki bulunan çok sayıda değişkeni bir araya getirerek, az sayıda kavramsal olarak anlamlı yeni değişkenler bulmayı sağlamaktadır. Barlett testi, faktör analizinin yapılabilmesi için ön varsayımlardan birisidir. $\mathrm{Bu}$ test sonucunda faktör analizine alınan değişkenler arasında bir ilişki olması beklenir. Barlett değerinin $\mathrm{p}<0.05$ olması değişkenler arasında bir ilişkinin olduğunu gösterir. Analizlerde, örneklemin yeterli olup olmadığının belirlenebilmesi için KaiserMeyer-Olkin (KMO) testi yapılmaktadır. İyi bir faktör analizi yapılabilmesi için KMO değerinin 0.60 '1n üzerinde olması gerekmektedir. $(13,16)$. RİBBÖ'nün KMO katsayısı ile hesaplanan örneklem yeterlilik değerinin 0.861 olduğu ve Barlett testi sonucunda ise değişkenler arasında ileri düzeyde anlamlı ilişki olduğu saptanmıştır $\quad(\mathrm{x} 2=165.4$, $\mathrm{p}=0.000)$. $\mathrm{Bu}$ bulgular neticesinde çalış1lan örneklem büyüklügünün yeterli ve verilerin analize uygun olduğu belirlenmiştir.

Ölçüm aracının iç tutarlığı, ölçeğin ölçülmek istenilen değişkeni ölçmede yetkin olduğunu gösteren güvenirliktir. Cronbach tarafından geliştirilen ve bir iç tutarlılık tahmin yöntemi olan alfa katsayısı güvenilirlik hesaplarında çok sık kullanılmaktadır. Özellikle Likert türü toplamalı ölçeklerde ölçek maddelerinin birbirleriyle ne ölçüde tutarlı olduğuna ilişkin bilgi verir (12). Alfa katsayısının yüksek olması, ölçeği oluşturan maddelerin birbirleri ile tutarlı veya başka bir deyişle ölçeğin aynı özelliğin öğelerini ölçen maddelerden oluştuğu söylenebilir. Alfa değeri 0.60-0.80 arasında olmas1 ölçeğin güvenilir olduğunu, 0.80-1.00 arasında olması ise ölçeğin yüksek güvenirliğe sahip olduğunu göstermektedir $(11,15)$. Geliştirdiğimiz bu ölçeğin Cronbach Alfa değeri 0.737'dir. Bu değer ölçeğin güvenilir olduğunu göstermektedir. İç tutarlılı̆̆ın olması için madde toplam puan korelasyonunun en az 0.30 olması gerekmektedir. $\mathrm{Bu}$ ölçekte madde toplam puan korelasyonları 0.30'un üzerinde olmasından dolayı ölçekten herhangi bir maddenin çıkarılmasına gerek duyulmamıştır.

Zamana göre değişmezlik, yapılan bir ölçümde kullanılabilecek güvenirlik ölçütlerinden biridir. Test-tekrar test güvenirliği bir ölçüm aracının yapılan her uygulamada tutarlı sonuçlar verebilmesi ve zamana göre değişmezlik gösterebilme gücüdür. Yeni geliştirilen ölçekler için test-tekrar test korelasyon katsayısının kabul edilebilir düzeyi 0.70'dir (13). Ölçeğin zaman içindeki kararlılığını belirlemek amacıyla 158 babaya ölçek 15 gün ara ile ikinci kez uygulanmıştır. Bu iki uygulama arasında Pearson Momentler Çarpımı korelasyon katsayısı $\mathrm{r}=0,87 \quad(\mathrm{p}<.05)$ olarak bulunmuştur. Açıklanan bu veriler 1şığında, RİBBÖ farklı zamanlarda tekrarlanan ölçümlerde, benzer sonuçları sağlama özelliğine sahiptir. Dolayısıyla geliştirdiğimiz ölçme aracı Türk toplumundaki babalar için güvenilir olarak kabul edilebilir.

\section{SONUÇ}

Bu çalışmada, RİBBÖ'nün eşleri 24-38 haftalık gebelik döneminde olan babaların, bebeklerine bağlanma durumlarının belirlenmesinde geçerligüvenilir tek faktörlü bir ölçek olarak kullanılabileceği sonucuna varılmıştır. Ölçeğin, prenatal dönemde farklı örneklem gruplarına, farklı özelliklere sahip gebelerin eşlerine, bebeklerine bağlanma düzeylerini belirlemek amaciyla tekrar uygulanması ve çalışmalarda kullanılması önerilmektedir.

\section{REFERENCES}

1. Güleç D, Kavlak O. Baba-bebek bağlanma ölçeği'nin türk toplumunda geçerlik ve güvenirliğinin incelenmesi. International Journal of Human Sciences, 2010;10: 170-181. 
2. Yilmaz SD, Beji NK. Prenatal bağlanma envanteri'nin türkçe'ye uyarlanması: güvenilirlik ve geçerlilik çalışması. Journal of Anatolia Nursing and Health Sciences 2013;16: 103-109.

3. Yalçın SS, Örün E, Özdemir $P$, et al. Reliability of the postpartum bonding scales in turkish mothers. Çocuk Sağlığı ve Hastalıkları Dergisi 2014; 57: 246-251.

4. Duyan V, Kapısız SG, Yakut Hİ. Doğum öncesi bağlanma envanteri'nin bir grup gebe üzerinde türkçeye uyarlama çalışması. The Journal of Gynecology - Obstetrics and Neonatology 2013;10: 1609-1614.

5. Verny TR, Kelly J. The secret life of the unborn child: how you can prepare your baby for a happy, Healthy Life. Dell,1982;204-8.

6. Başbakkal Z. Babaların bebek bakımındaki rolü, ege üniversitesi hemşirelik yüksekokulu, yayınlanmamış yüksek lisans tezi, 1999.

7. Karakulak AH, Alparslan Ö. Anne-bebek bağlanma ölçeğinin türk toplumuna uyarlanmasi: Aydın örneği. Journal Of Contemporary Medicine 2016;6:188-199.

8. Akgül A. Faktör analizi. Tıbbi araştırmalarda istatistiksel analiz teknikleri SPSS uygulamaları. Ankara: Emek Ofset; 2005;34.

9. Şencan H. Sosyal ve davranışsal ölçümlerde güvenilirlik ve geçerlilik. Ankara: Seçkin Yayıncılık; 2005.

10. Fletcher R, May C, St George J. A fathers prenatal relationship with 'their' baby and 'her' pregnancy - implications for antenatal education. International Journal of Birth \& Parent Education 2014;1: 23-2.

11. Önler E, Varol Saraçoğlu G. Hemşirelikte meslek seçimi ölçeğinin güvenilirlik ve geçerliliği. DEUHYO ED 2010;3: 78-85.

12. Tuz C, Öksüz ME, Tekiner AS. Kadına yönelik şiddet derecelendirme ölçeği ve mağdurların cinsel deneyimleri ölçeği türkçe versiyonunun geçerlilik ve güvenilirliği. Euras J Fam Med 2015;4: 83-89.

13. Çınar Ş, Demir Y. Toplumdaki hemşirelik imaj1: bir ölçek geliştirme çalışması, Atatürk
Üniversitesi Hemşirelik Yüksekokulu Dergisi. 2009;12: 24-33.

14. Kavlak O, Şirin A. Maternal bağlanma ölçeği'nin türk toplumuna uyarlanması. Uluslararası İnsan Bilimleri Dergisi. 2009;6:188-202.

15. Dost A, Bahçecik AN. Hemşirelik mesleğine yönelik imaj ölçeği geliştirilmesi. JAREN 2015;1:51-59.

16. Alp Dal N, Ertem G. Jinekolojik kanserler farkındalık ölçeği geliştirme çalışması. İnsan ve Toplum Bilimleri Araştırmaları Dergisi. 2017; 6:2351-2367. 